\title{
$\mathrm{HLA}-\mathrm{B} 27$ 연관 앞포도막염의 형광안저혈관조영술 소견과 포도막염 재발과의 관련성
}

\section{Fluorescein Angiographic Findings and Recurrence of Human Leukocyte Antigen-B27-Associated Anterior Uveitis}

\author{
이종섭·류소정·이병로 · 안성준 \\ Jong Sub Lee, MD, So Jung Ryu, MD, Byung Ro Lee, MD, PhD, Seong Joon Ahn, MD, PhD \\ 한양대학교 의과대학 한양대학교병원 안과학교실 \\ Department of Ophthalmology, Hanyang University Hospital, Hanyang University College of Medicine, Seoul, Korea
}

\begin{abstract}
Purpose: To evaluate the associations of fluorescein angiographic findings with recurrence of human leukocyte antigen (HLA)-B27-associated anterior uveitis.

Methods: Medical records of 56 eyes of 56 patients with first-onset, treatment-naive HLA-B27-associated anterior uveitis who performed fluorescein angiography was analyzed. We recorded the fluorescein angiographic findings of optic disc and peripheral vascular leakage and anterior chamber inflammation at the first visit. The 1-year recurrences and times to the first recurrences and the associations between them were investigated.

Results: Fluorescein angiography revealed optic disc leakage in 23 patients $(41.1 \%)$ and peripheral vascular leakage in 36 (64.3\%). We found no significant association between the anterior chamber inflammation grade and either optic disc $(p=0.841)$ or peripheral vascular $(p=0.775$ ) leakage. The 1-year recurrence rate in the optic disc leakage-positive group was significantly higher than in the leakage-negative group (14 patients, $60.9 \%$ vs. 11 patients, $33.3 \%)(p=0.041)$, but peripheral vascular leakage status did not significantly affect the recurrence rate (19 leakage-positive patients, $52.8 \%$ vs. 8 leakage-negative patients, $40.0 \%)(p=0.602)$. The time to first recurrence was not significantly associated with age $(p=0.772)$, anterior chamber inflammation ( $p=0.841)$, optic disc leakage $(p=0.108)$, or systemic corticosteroid use $(p=0.321)$.

Conclusions: We sought correlations between angiographic leakage in patients with HLA-B27-associated anterior uveitis, and the 1-year recurrence rate and the time to first recurrence. Careful follow-up for at least 1 year after initial diagnosis is essential to monitor possible recurrence in patients with optic disc leakage.
\end{abstract}

J Korean Ophthalmol Soc 2021;62(10):1364-1369

Keywords: Anterior uveitis, Fluorescein angiography, Human leukocyte antigen-B27, Recurrence

- Received: 2021. 4. 7.

- Revised: 2021. 6. 2

- Accepted: 2021. 9. 28.

- Address reprint requests to Seong Joon Ahn, MD, PhD Department of Ophthalmology, Hanyang University Hospital, \#222-1 Wangsimni-ro, Seongdong-gu, Seoul 04763, Korea Tel: 82-2-2290-8570, Fax: 82-2-2296-6236

E-mail: ahnsj81@gmail.com

* This study was Supported by a National Research Foundation of Korea Grant funded by the Korean Government Ministry of Science and ICT (NRF-2021M3E5D1A01015175 and 2021R1G1A1013360).

* Conflicts of Interest: The authors have no conflicts to disclose.
앞포도막염은 전방에 발생하는 염증이 특징인 질환으로 ${ }^{1}$ 전 세계에서 약 $50-90 \%,{ }^{2-4}$ 국내에서는 약 $28 \%$ 를 차지하는 가장 흔한 형태의 포도막염이다. ${ }^{5}$ 다른 포도막염 형태와 마 찬가지로 앞포도막염 역시 전신질환과 연관되어 발생할 수 있으며, 대표적인 질환으로 사르코이드증, 강직성 척추염, 베체트병, 염증성 장질환 등이 알려져 있다. ${ }^{6}$ 앞포도막염은 혈청학적으로는 human leukocyte antigen (HLA)-B27 표현 형과의 관련성이 잘 알려져 있다. HLA-B27 관련 앞포도막 
염은 앞포도막염의 중요한 원인으로 보고되었고, 전체 앞 포도막염 중 약 $1-23 \%$ 를 차지하는 것으로 보고되었다. ${ }^{4,5}$

포도막염 환자에서 망막혈관 변화는 그 형태에 따라 다 양하게 나타난다. 형광 누출, 혈관염 소견 등이 포도막염에 수반된 혈관의 염증성 변화에 의해 나타날 수 있으며, 이는 주로 중간포도막염 및 뒤포도막염에서 나타난다. 앞포도막 염 환자에서의 후부 변화는 상대적으로 잘 알려져 있지 않 으나 낭포황반부종, 시신경염, 망막혈관염, 편평부 삼출물 등이 나타날 수 있음이 보고되었다. ${ }^{7,8}$ 또한 앞포도막염 환 자에서 임상적 증상이 없는 경우에도 형광안저혈관조영술 상 혈관 누출이 있는 경우가 몇몇 연구에서 보고되고 있 다. ${ }^{7,9,10} 2019$ 년 시행한 연구에서 Thomas et $\mathrm{al}^{9}$ 은 42 명 73 안 의 포도막염 환자에게 광범위 형광안저혈관조영술을 시행 하였고, 치료 시작 시 주변부혈관누출이 있는 경우에는 임 상적으로 활동적인 경우가 많고 낭포황반부종이 동반되거
나 더욱 강한 치료를 받는 경우가 많으나 최종 시력예후는 유의한 차이가 없음을 확인하였다. 다만 몇몇 연구를 제외 하고는 앞포도막염 환자에서 형광안저혈관조영술상 혈관 누출의 유무 및 혈관 누출의 위치에 따른 임상적 의미에 대 한 연구는 아직 부족한 실정이다.

이에 본 연구에서는 HLA-B27 연관 앞포도막염 환자에 서 형광안저혈관조영술에서 나타나는 주변부혈관 혹은 시 신경유두누출의 유무와 초진 시 전방염증의 정도, 첫 발생 후 1 년 내 재발과의 관련성을 분석하였다. 또한 앞포도막염 이 재발한 경우 재발까지의 시기에 영향을 미치는 요인에 대해 조사하였다.

\section{대상과 방법}

본 연구는 헬싱키선언(Declaration of Helsinki)을 준수하
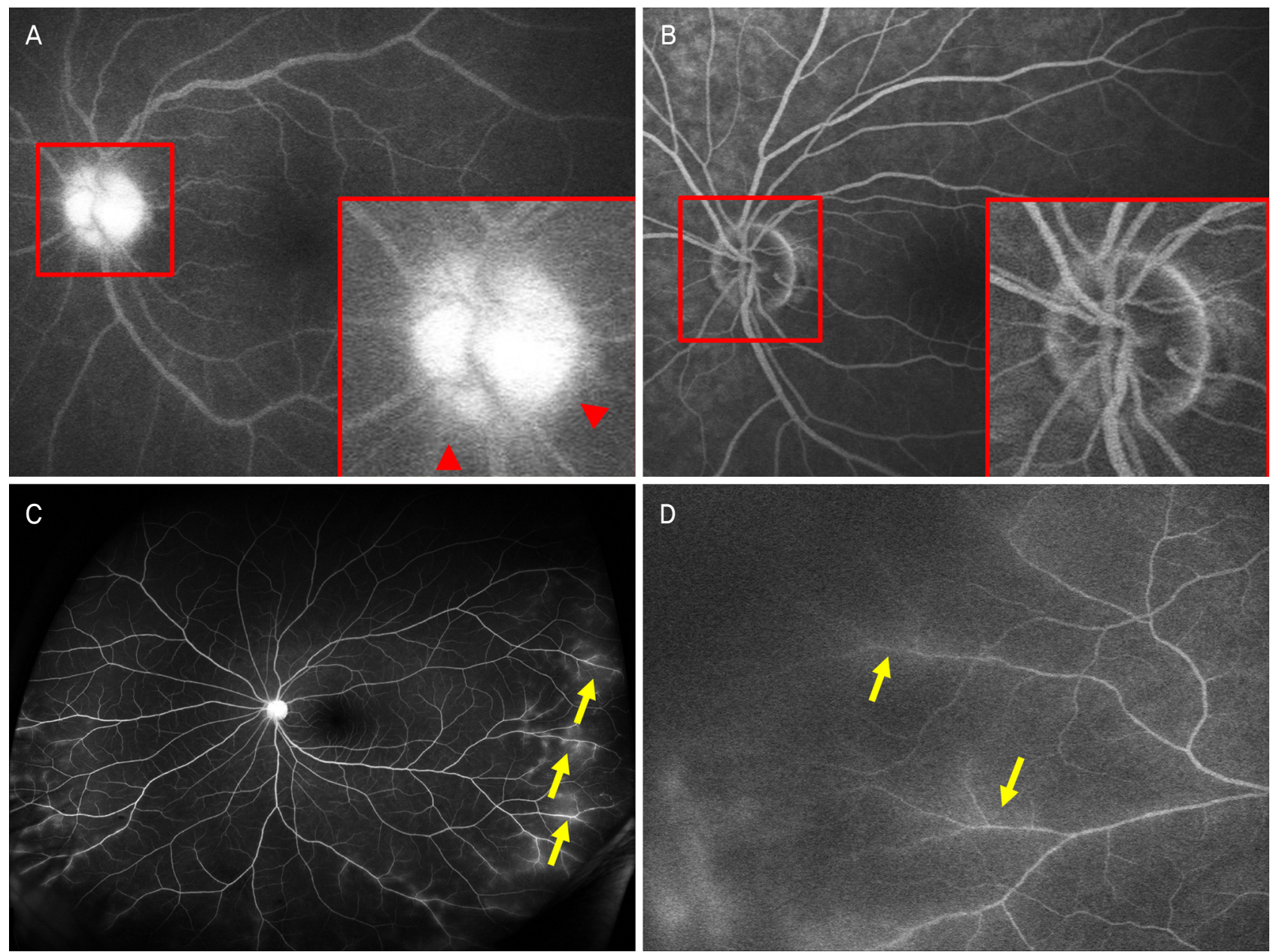

Figure 1. Representative cases of the study were shown. Optic disc leakage with extravascular localization of the dye on the optic disc (denoted as red arrowheads) was remarkable in (A), comparable with negative optic disc leakage in (B). Peripheral vascular leakage was shown as fluorescence leakage on the peripheral retinal vessels (denoted as yellow arrows) on the ultrawide-field fluorescein angiography in $(\mathrm{C})$, and standard confocal scanning laser ophthalmoscopy image in (D). 
였으며 본원 연구윤리심의위원회(Institutional Review Board, IRB)의 승인을 받았다(승인 번호: 2021-04-052). 한양대학 교병원에서 2014년 1월부터 2019년 8월까지 HLA-B27 혈 청학적 검사에서 양성 판정을 받은 환자들 가운데 포도막 염 병력 혹은 치료력이 없으며, 이외 다른 포도막염 관련 혈청학적 인자는 음성을 보인 급성 앞포도막염이 있는 환 자 중 형광안저혈관조영술을 시행하였던 환자들의 의무기 록을 후향적으로 분석하였다. 형광안저혈관조영술 영상 해 석에 영향을 줄 수 있는 매체 혼탁, 망막 및 황반질환 병력, 안구 외상력, 일반적인 백내장수술을 제외한 안구내 수술 의 병력이 있는 경우 배제하였다. 백내장수술의 경우도 6 개 월 이내에 수술한 병력이 있는 경우 배제하였다. 수집된 진 료 정보에는 환자의 성별, 연령, 굴절력, 초진 시 전방염증 의 정도, 경과 관찰 시 포도막염 재발 여부, 재발까지의 개 월 수, 사용한 치료법이 포함되었다.

모든 환자에서 최초로 내원하였을 때 자세한 병력 청취 를 시행하여 과거 포도막염 병력, 치료력을 확인하였다. 매 내원 시 시력, 비접촉안압계, 자동굴절계, 세극등현미경검사, 안저검사, 광각안저촬영, 빛간섭단층촬영을 시행하였다. 전 방과 유리체의 염증 정도는 Standardization of the Uveitis Nomenclature Working Group (SUN) criteria에 따라 평가 하였다. ${ }^{1}$ 굴절력은 자동굴절계(KW-1500, Kowa, Nagoya, $\mathrm{Japan}$ )를 이용하여 측정하였으며, 안압은 자동비접촉안압 계(KT-500 automated tonometer, Kowa, Nagoya, Japan)를 이용하여 측정하였다. 빛간섭단층촬영은 파장가변빛간섭단 층촬영기(DRI-OCT, Topcon Inc., Tokyo, Japan)를 이용하 여 촬영하였고 망막의 $12 \times 9 \mathrm{~mm}$ 영역의 광범위한 영상을 통해 망막의 이상 여부를 확인하였다.

앞포도막염 최초 진단 후 1 주 이내 형광안저혈관조영술 을 시행하였다. 형광안저혈관조영술은 공초점레이저검안경 (F-10, Nidek, Gamagori, Japan)을 이용하여 시행하였으며, 전주정맥에 $25 \%$ sodium fluorescein 용액 $5 \mathrm{~mL}$ 를 주사 후, 양안의 촬영을 시행하였다. 주사 후 7-8초 후부터 촬영을 시작하였고, 수초 간격으로 촬영을 하여 후극부 영상을 얻 었다. 맥락막 재순환기 이후에는 주변부 망막도 함께 촬 영하였고, 주사 후 15-20분까지 촬영하여 후기 영상을 얻 었다. 이후 광각안저촬영기(Optos California, Optos PLC, Dunfermline, UK)로 추가 촬영하여 주변부 형광 누출을 잘 확인할 수 있도록 하였다. 포도막염 최초 진단 시 선별검사 를 위해 흥부방사선촬영 및 일반혈액검사, 혈액일반화학검 사, 인간면역결핍바이러스항체검사, 매독항체검사, 류마토 이드인자검사, 안지오텐신전환효소검사, HLA-B27 등 항목 이 포함된 혈액검사를 시행하였다.

형광안저혈관조영술 영상을 통해 시신경유두누출 여부,
주변부혈관누출 여부를 평가하였다. 과거 연구의 정의를 토대로 시신경유두누출은 형광안저혈관조영 시 후기에 정 상적인 시신경유두의 조영보다 시신경유두 주변 누출로 인 한 조영이 더 밝게 나타나는 경우로 정의하였고 ${ }^{11,12}$ 주변부 혈관누출은 망막 주변부 혈관 주위에 형광 누출이 있는 경 우로 정의하였다(Fig. 1). ${ }^{9}$ 모든 경우 반대안의 영상을 참고 하며 비교하여 판정하였다. 판정 시 독립된 두 명의 안과 전문의가 환자 관련 임상 정보에 대한 가림을 적용하여 수 행하였으며, 평가자 사이의 불일치가 있을 경우 두 명이 모 두 누출이 있다고 한 경우를 양성으로 판정하였다. 두 명의 평가자 간의 일치도(Cohen's kappa, $\kappa)$ 는 0.787로 높은 일 치도를 보였다.

급성 앞포도막염의 치료를 위해 의사의 임상적 판단에 따라 점안 스테로이드(Prednilone oph soln; Prednisolone acetate $1 \%$, Daewoo Pharma. Co., Ltd., Busan, Korea) 및 조절마비제(Ocucyclo, Cyclopentolate hydrochloride 1\%, Samil Pharm. Co., Ltd., Seoul, Korea)를 사용하였으며, 3+ 이상의 심한 전방염증에 대해서는 경구 스테로이드를 초기 에 체중당 $0.5 \mathrm{mg} / \mathrm{kg}$ 의 일일 용량을 사용하여 경과에 따라 천천히 감량하였다. 이외 조절이 안되거나 전방축농 등 매 우 심한 안내 염증에 대해서는 트리암시놀론 테논낭하 주 사를 병행하였다.

데이터 분석은 IBM SPSS ver. 18.0 (IBM Corp., Armonk, $\mathrm{NY}, \mathrm{USA}$ ) 통계프로그램을 사용하였다. 시신경유두누출 및 주변부혈관누출과 전방염증 정도의 정도 분석은 피셔정확 검정(Fisher's exact test)을 이용하였다. 1년 내 재발 여부와 시신경유두누출 및 주변부혈관누출의 빈도 간 관련성 분석 에는 카이제곱검정(chi square test)을 이용하였다. 또한, 재 발이 발견된 환자에서 재발까지의 기간과 연령, 초진 시 전 방염증의 정도, 경구 스테로이드의 사용 여부, 시신경유두 누출 및 주변부혈관누출의 연관성을 분석하고자 콕스 비례 위험모형 회귀분석(Cox proportional hazards model)을 적 용하였다. 모든 통계적 검정은 유의수준 0.05 미만인 경우 를 통계적으로 유의하다고 판정하였다.

\section{결 과}

대상자는 총 56명 56안의 HLA-B27 양성 급성 앞포도막 염 환자이며, 성별은 주로 남성이 흔하였고(43명, $76.8 \%$ ) 평균 연령은 39.6세(17-70세)였다. 모든 환자에서 단안성으 로 발현하였으며, 우안 29안, 좌안 27안이 포함되었다. 진 단 당시 전방염증은 $\mathrm{SUN}$ criteria상 $1+, 2+, 3+, 4+$ 가 각각 9안(16.1\%), 20안(35.7\%), 16안(28.6\%), 11안(19.6\%)이 관 찰되었다. 전방염증 단계 $0.5+$ 인 환자는 관찰되지 않았다. 
모든 환자에서 점안 스테로이드, 경구 혹은 테논낭하 스테 로이드 병합 요법으로 염증은 호전되었다. 진단 후 1 주 이 내에 시행한 형광안저혈관조영술에서 시신경유두누출이 발견된 경우는 23명(41.1\%), 주변부혈관누출이 발견된 경 우는 36 명 $(64.3 \%)$ 이었다. 진단 후 1년 내 재발이 발견된 경 우는 25 명 $(44.6 \%)$ 이었다(Table 1).

형광안저혈관조영술상 누출과 전방염증 사이의 상관 관 계를 분석하였다. 시신경유두누출은 전방염증이 심할수록 더 빈번하게 나타나는 경향을 보였으나, 통계적으로 유의 한 관계를 보이지는 않았다 $(p=0.705)$. 마찬가지로 전방염증 의 단계와 주변부혈관누출의 빈도 또한 통계적으로 유의한 관계를 보이지 않았다 $(p=0.775)$ (Table 2).

시신경유두누출과 1 년 내 재발과의 상관성을 분석해보 면, 시신경유두누출이 있는 군에서 1 년 내에 재발한 경우는 14 명 $(60.9 \%)$ 인데 반해, 누출이 없는 군에서 1년 내에 재발 한 경우는 11 명(33.3\%)으로 통계적으로 유의한 차이를 보 였다 $(p=0.041)$. 반면, 주변부혈관누출이 있는 군에서 1 년 내 재발한 경우 17 명(47.2\%)이고 누출이 없는 군에서 1 년

Table 1. Clinical characteristics of eyes with human leukocyte antigen-B27 associated anterior uveitis

\begin{tabular}{lc}
\hline Characteristic & Value \\
\hline Age (years) & $39.6 \pm 12.7(17$ to 70$)$ \\
Sex (male) & $43(76.8)$ \\
Laterality of uveitic eye (right) & $29(51.8)$ \\
Spherical equivalent (diopters) & $-2.25 \pm 1.83(-6$ to +1$)$ \\
Inflammation grade (grade & $0: 9: 20: 16: 11$ \\
$0.5+: 1+: 2+: 3+: 4+)^{*}$ & $(0: 16.1: 35.7: 28.6: 19.6)$ \\
1-year recurrence & $25(44.6)$ \\
Optic disc leakage & $23(41.1)$ \\
Peripheral vascular leakage & $36(64.3)$ \\
\hline
\end{tabular}

Values are presented as mean \pm standard deviation or number (\%). *The Standardization of the Uveitis Nomenclature working group classification.
내 재발한 경우는 8 명 $(40.0 \%)$ 으로 측정되어, 주변부혈관누 출이 있는 경우 재발률이 높게 나타났으나 이는 통계적으 로 유의한 차이는 아니었다 $(p=0.602)$ (Table 3). 한편, 전신 스테로이드 사용 여부와 1년간 포도막염 재발 여부는 유의 한 상관 관계를 갖지 않았다 $(p=0.952)$. 앞포도막염의 발생 으로부터 첫 재발까지의 기간에 관련되어 있는 임상 인자 를 분석하고자 회귀분석을 적용한 결과, 첫 재발까지의 기 간에 대해 나이 $(p=0.772)$, 전방염증 정도 $(p=0.841)$, 시신경 유두누출 $(p=0.108)$, 전신 스테로이드 사용 여부 $(p=0.321)$ 는 유의한 상관관계를 보이지 않았다.

\section{고 찰}

본 연구에서는 중간 및 뒤포도막염에서 망막 및 망막혈 관의 변화를 관찰하기 위해 흔하게 사용하는 검사인 형광 안저혈관조영술을 대표적인 앞포도막염인 HLA-B27 연관 앞포도막염에 적용하여 망막 및 망막혈관의 변화를 관찰하 였다. 이를 통해 앞포도막염에서는 망막염 등 뒤포도막염 에서 나타나는 소견은 관찰할 수 없었으나, $41.1 \%$ 의 환자 에서 시신경유두누출 및 $64.3 \%$ 의 환자에서 주변혈관누출

Table 3. Fluorescein angiographic findings and 1-year recurrence of eyes with human leukocyte antigen-B27 associated anterior uveitis

\begin{tabular}{|c|c|c|c|}
\hline \multirow{2}{*}{$\begin{array}{l}\text { Fluorescein angiographic } \\
\text { findings }\end{array}$} & \multicolumn{2}{|c|}{ 1-year recurrence } & \multirow{2}{*}{$p$-value } \\
\hline & Yes & No & \\
\hline Optic disc leakage & & & 0.041 \\
\hline Yes $(n=23)$ & $14(60.9)$ & $9(39.1)$ & \\
\hline No $(n=33)$ & $11(33.3)$ & $22(66.7)$ & \\
\hline Peripheral leakage & & & 0.602 \\
\hline Yes $(n=36)$ & $17(47.2)$ & $19(52.8)$ & \\
\hline No $(n=20)$ & $8(40.0)$ & $12(60.0)$ & \\
\hline
\end{tabular}

Values are presented as number (\%).

${ }^{*}$ Chi-square test.

Table 2. Fluorescein angiographic findings and grade of anterior chamber inflammation of eyes with human leukocyte antigen-B27 associated anterior uveitis

\begin{tabular}{|c|c|c|c|c|c|c|}
\hline \multirow{2}{*}{ Fluorescein angiographic finding } & \multicolumn{5}{|c|}{ Grade of anterior chamber inflammation (SUN classification) } & \multirow{2}{*}{$p$-value ${ }^{*}$} \\
\hline & $0.5+$ & $1+$ & $2+$ & $3+$ & $4+$ & \\
\hline Optic disc leakage & & & & & & 0.705 \\
\hline Yes $(n=23)$ & 0 & $6(26.1)$ & $5(21.7)$ & $4(17.4)$ & $8(34.8)$ & \\
\hline No $(\mathrm{n}=33)$ & 0 & $7(21.2)$ & $9(27.3)$ & $9(27.3)$ & $8(24.2)$ & \\
\hline Peripheral leakage & & & & & & 0.775 \\
\hline Yes $(n=36)$ & 0 & $8(22.2)$ & $10(27.8)$ & $7(19.4)$ & $11(30.6)$ & \\
\hline No $(n=20)$ & 0 & $5(25.0)$ & $4(20.0)$ & $6(30.0)$ & $5(25.0)$ & \\
\hline
\end{tabular}

Values are presented as number $(\%)$.

SUN = the Standardization of the Uveitis Nomenclature working group.

*Fisher's exact test. 
소견을 확인할 수 있었다. 또한 시신경유두유출은 1년 내 재발 여부와 유의한 상관관계를 가진다는 점을 확인하였다.

본 연구에서 시신경유두누출은 23 명, 주변부혈관누출은 36 명에서 발견되어 HLA-B27 연관 앞포도막염 환자의 $41.1 \%$ 및 $64.3 \%$ 에서 관찰되었고 이는 Yang et $\mathrm{al}^{7}$ 이 보고 한 시신경 과형광의 빈도인 $5.4 \%$ 와 비교해보면 다소 높은 수치이다. 기존 연구에서 방법론이 자세히 기술되지 않아 위 연구에서 조사한 시신경 과형광의 방법이 본 연구의 시 신경유두누출 평가 방법과 일치하는지 직접적 비교가 어려 운 가운데, 평가 방법, 환자군의 특성 등의 차이로 인해 빈 도차가 발생 가능하며, 본 연구에서는 적은 수의 환자로 인 한 선택 편향 가능성이 있어 후속 연구에서 더 많은 환자들 을 대상으로 빈도를 재조사할 필요가 있을 것으로 생각된다.

앞포도막염은 SUN criteria에서 안구의 앞부분, 전방에 주로 국한되는 염증을 의미하나 ${ }^{1}$ 안구의 염증으로 인한 혈 관의 반응은 보다 광범위하게 일어날 수 있고, 앞포도막염 에서도 이에 의한 안구의 혈관 변화가 본 연구의 형광안저 혈관조영술에서 망막혈관의 누출로 나타나는 것으로 사료 된다. 대표적인 안구의 혈관층인 맥락막의 경우, HLA-B27 앞포도막염에서 맥락막혈관이 확장되며, 이에 의한 맥락막 두께가 증가하는 현상을 최근 연구에서 보고한 바 있다. ${ }^{13,14}$ 이러한 현상의 일환으로, 광범위한 혈관 확장 및 혈관 투과 성 증가가 조영제의 누출을 일으켰을 것으로 생각되며, 본 가설은 추후 연구에서 혈관 투과성에 대한 평가를 통해 검 증되어야 할 것이다.

본 연구에서는 시신경유두누출은 1년 내 재발 여부와 유 의한 상관관계가 있었고 재발까지의 기간 역시 경계적 유 의성을 보였으나, 주변부 혈관 누출은 재발과의 유의한 관 련성이 확인되지 않았다. 유의하지는 않았지만 일반적으로 시신경유두누출이 있는 경우 전방염증의 단계도 높은 양상 을 보여, 병의 활성도가 높아 재발 경향도 높은 것으로 해 석할 수 있다. 반면, 주변부혈관누출은 전방염증 및 재발과 특별한 연관성이 없었고, 이는 Yang et $\mathrm{al}^{7}$ 에 의해 주변부혈 관누출과 앞포도막염의 임상양상은 특별한 관련성이 없다 고 보고된 것과 일치하는 결과이다. 특히, 정상안에서도 주 변부혈관누출이 관찰될 수 있고 최근 연구에서는 발생률이 $32.5 \%$ 까지 보고되어 ${ }^{15}$ 이 변화가 과연 앞포도막염으로 인 한 변화인지 역시 명확하지 않다. 시신경유두누출, 주변부 혈관누출의 기전 및 앞포도막염과의 명확한 관련성에 대해 서는 후속 연구가 필요할 것으로 생각된다.

현재 HLA-B27 연관 앞포도막염의 재발을 예측할 수 있 는 도구가 거의 없는 현실에서, 형광안저혈관조영술을 통 한 망막혈관 평가는 망막 및 망막혈관의 동반된 이상을 확 인할 수 있을 뿐만 아니라 앞포도막염의 재발을 예측하는
데 도움이 된다는 측면에서 급성 염증 발생 시 고려해 볼 수 있다. 검사상 시신경유두 누출이 관찰되는 환자에서는 재발 가능성에 대해 조금 더 면밀한 경과 관찰이 필요할 것 으로 생각된다. 다만 이런 환자들을 경구 스테로이드 병합 등 조기에 적극적인 치료가 필요한지에 관해서는 본 연구 의 범위 밖으로, 후속 연구를 통해 치료에 따른 그 임상 경 과를 알아봄으로써 결과를 도출해야 할 것으로 생각된다.

앞포도막염은 다양한 원인으로 발생할 수 있고 이런 원 인 기전의 차이로 인해 혈관에 대한 염증의 차이를 야기할 수 있다. 본 연구에서는 흔한 앞포도막염의 원인 중 하나인 HLA-B27 관련 앞포도막염만을 대상으로 하여, 다양한 원 인에 의한 교란 효과를 최소화하고자 하였다. 이를 통해 형 광안저혈관조영술의 변화와 염증 정도 간 상관관계 및 1년 내 재발과의 관련성을 분석할 수 있었다. 단, 본 연구의 결 과가 앞포도막염 전반에 대해 적용될 수 있을지는 다양한 원인의 앞포도막염에 대해서도 형광안저혈관조영술을 통 해 검증되어야 할 것이다. 또한, 검사 거부, 경과 관찰 탈락 등 다양한 상황에 의해 연구에서 배제된 환자들이 있어 후 향적 연구 본연이 가지는 선택 편향의 가능성이 존재한다. 그리고 본 연구에서 전방 및 유리체의 염증 정도에 대한 평 가는 의무 기록에서 확인되는 한 명의 담당의에 의한 평가 결과를 사용하였는데 연구의 객관성을 높이기 위해 두 명 의 전문의가 독립적으로 염증 정도를 평가하는 것이 더 바 람직하며, 이는 추후 전향적 연구를 통해 본 연구의 결과가 재확인될 필요성이 있다. 또한 다수의 환자를 통해 분석이 이뤄지지 않아 생존 분석 관련 통계가 유의하지 않았을 가 능성이 있어, 더 많은 수의 환자를 포함한 후속 연구가 필 요할 것으로 생각된다. 또 1 년 내 재발 여부를 관찰하였으 나, 더 긴 경과 관찰 기간에 대해서는 결과가 어떻게 될지 장기간 추적 결과에 후속 연구가 필요할 것으로 사료된다.

결론적으로, 본 연구에서는 HLA-B27 연관 앞포도막염 환자에서 형광안저혈관조영술을 이용한 시신경유두유출 여부가 1 년 내 재발과 연관성이 있음을 확인하였다. 본 연 구 결과를 바탕으로, HLA-B27 연관 앞포도막염으로 첫 진 단되는 환자에서 형광안저혈관조영술을 고려해볼 수 있으 며, 시신경유두누출이 있는 경우 향후 1년간 조금 더 면밀 한 경과 관찰을 통해 재발 여부를 확인해야 할 것으로 생각 된다.

\section{REFERENCES}

1) Jabs DA, Nussenblatt RB, Rosenbaum JT; Standardization of Uveitis Nomenclature (SUN) Working Group. Standardization of uveitis nomenclature for reporting clinical data. Results of the First International Workshop. Am J Ophthalmol 2005;140:509-16. 
2) Acharya NR, Tham VM, Esterberg E, et al. Incidence and prevalence of uveitis: results from the Pacific Ocular Inflammation Study. JAMA Ophthalmol 2013;131:1405-12.

3) McCannel CA, Holland GN, Helm CJ, et al. Causes of uveitis in the general practice of ophthalmology. UCLA Community-Based Uveitis Study Group. Am J Ophthalmol 1996;121:35-46.

4) Chang JH, Wakefield D. Uveitis: a global perspective. Ocul Immunol Inflamm 2002;10:263-79.

5) Chung H, Choi DG. Clinical analysis of uveitis. Korean J Ophthalmol 1989;3:33-7.

6) Khan MA. HLA-B27 and its pathogenic role. J Clin Rheumatol 2008;14:50-2.

7) Yang P, Wan W, Du L, et al. Clinical features of HLA-B27-positive acute anterior uveitis with or without ankylosing spondylitis in a Chinese cohort. Br J Ophthalmol 2018;102:215-9.

8) Dodds EM, Lowder CY, Meisler DM. Posterior segment inflammation in HLA-B27+ acute anterior uveitis: clinical characteristics. Ocul Immunol Inflamm 1999;7:85-92.

9) Thomas AS, Redd T, Campbell JP, et al. The impact and implication of peripheral vascular leakage on ultra-widefield fluorescein angiography in uveitis. Ocul Immunol Inflamm 2019;27:
349-55.

10) Chi Y, Guo C, Peng Y, et al. A prospective, observational study on the application of ultra-wide-field angiography in the evaluation and management of patients with anterior uveitis. PLoS One 2015;10:e0122749.

11) Park HY, Jeong HJ, Kim YH, Park CK. Optic disc hemorrhage is related to various hemodynamic findings by disc angiography. PLoS One 2015; 10:e0120000.

12) Arend O, Remky A, Plange N, et al. Fluorescein leakage of the optic disc in glaucomatous optic neuropathy. Graefes Arch Clin Exp Ophthalmol 2005;243:659-64.

13) Ahn SJ, Kim JH, Lee BR. Choroidal change in acute anterior uveitis associated with human leukocyte antigen-B27. PLoS One 2017; 12:e180109.

14) Kim M, Choi SY, Park YH. Analysis of choroidal and central foveal thicknesses in acute anterior uveitis by enhanced-depth imaging optical coherence tomography. BMC Ophthalmol 2017;17:225.

15) Wang $X, X u A, Y i Z$, et al. Observation of the far peripheral retina of normal eyes by ultra-wide field fluorescein angiography. Eur J Ophthalmol 2021;31:1177-84.

\section{= 국문초록 $=$}

\section{HLA-B27 연관 앞포도막염의 형광안저혈관조영술 소견과 포도막염 재발과의 관련성}

목적: HLA-B27 연관 앞포도막염의 형광안저혈관조영술 소견과 재발의 관련성을 연구하였다.

대상과 방법: 최초로 진단 받고 치료를 시작한 HLA-B27 연관 앞포도막염 환자 중 형광안저혈관조영술을 시행한 56명(56안)의 의무기 록을 후항적으로 검토하였다. 형광안저혈관조영술상 시신경유두누출, 주변부혈관누출 유무와 초진 시 전방염증의 정도, 1 년 내 재발 과의 관련성, 재발까지의 시기에 영향을 미치는 요인과의 연관성에 대해 분석하였다.

결과: 총 56명(56안)의 환자 중 시신경유두누출이 발견된 경우는 23 명(41.1\%), 주변부혈관누출이 발견된 경우는 36 명(64.3\%)이었다. 시신경유두누출 $(p=0.841)$ 혹은 주변부혈관누출 $(p=0.775)$ 과 전방염증의 정도는 유의한 관계를 보이지 않았다. 시신경유두누출이 있는 군의 1 년 내 재발은 14 명 $(60.9 \%)$, 없는 군의 1 년 내 재발은 11 명(33.3\%)으로 두 군은 유의한 차이를 보였다( $p=0.041)$. 반면 주변부혈관 누출이 있는 군의 1년 내 재발은 19 명(52.8\%), 없는 군의 1년 내 재발은 8 명(40.0\%)으로 유의한 차이를 보이지 않았다( $p=0.602)$. 하지 만 첫 재발까지의 기간에 대해 나이 $(p=0.772)$, 전방염증 정도 $(p=0.841)$, 시신경유두누출( $p=0.108)$, 전신 스테로이드 사용 여부 $(p=0.321)$ 는 유의한 상관관계를 보이지 않았다.

결론: HLA-B27 연관 앞포도막염에서 형광안저혈관조영술상 누출과 1년 내 재발 여부 및 재발까지의 기간 사이의 관계를 확인하였다. 시신경유두누출이 있는 경우 1년간 면밀한 경과 관찰을 통해 재발 여부를 확인해야 할 것으로 생각된다.

〈대한안과학회지 2021;62(10):1364-1369〉

이종섭 / Jong Sub Lee

한양대학교 의과대학 한양대학교병원 안과학교실

Department of Ophthalmology,

Hanyang University Hospital,

Hanyang University College of Medicine

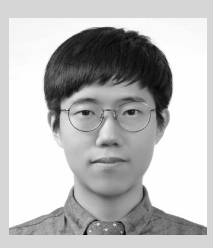

